\title{
Effects of Dietary Fat Levels on Amino Acid Digestibility at Different Sites of Chicken Intestines
}

\author{
Kazuhisa Honda, Hiroshi Kamisoyama, Shinpei Kubo, Tomoki Motoori and Shin Hasegawa \\ Graduate School of Agricultural Science, Kobe University, Kobe 657-8501, Japan
}

\begin{abstract}
The present study was conducted to investigate the effects of varying dietary fat levels $(3 \%-10 \%)$ on amino acid digestibility at different sites of fistulized chicken intestines. Chickens were fistulized to either the middle part of the jejunum (MJ), the distal end of the jejunum (DJ), the middle part of the ileum, the distal end of the ileum or the distal end of the rectum. Intestinal digesta were collected from each site of the intestine, and contents of amino acids were measured. True digestibilities of individual amino acids were not affected by the sites of intestines in the 3, 5 and $8 \%$ fat groups. The true digestibility of total amino acid in intestinal digesta at the MJ was significantly lower than that at the DJ in the $10 \%$ fat group. In addition, true digestibilities of individual amino acids at the MJ tended to be lower than those at the DJ in the $10 \%$ fat group. Comparison of the data at the MJ between groups showed that the true digestibilities of total amino acid and Met in intestinal digesta in the $10 \%$ fat group were significantly lower than those in other groups. The true digestibilities of all amino acids, except for Met, in intestinal digesta at the MJ in the 10\% fat group tended to be lower than those in other groups. These results suggest that dietary fat levels influence the digestion of amino acids at the proximal part of the jejunum in chickens.
\end{abstract}

Key words: amino acids, digestibility, ileum, jejunum, rectum

\section{Introduction}

Accurate diet formulation for domestic animals requires information on digestible rather than gross amino acid contents of feed protein. Consequently, several methods have been developed to allow the in vivo determination of nutrient digestibilities. These methods involve the sampling and analysis of intestinal digesta or excreta from intact or caecectomized birds. However, usefulness of these methods has often been questioned. For example, gut microflora, found mainly in the caeca and colon, may influence the amino acid composition of the excreta (Ten Doeschate et al., 1993). Caecectomy has been used by several researchers to minimize the effects of the microflora, but research to date on the effect of caecectomy on excreta amino acid digestibility has produced variable results (Johns et al., 1986; Green et al., 1987a; 1987b; Longstaff et al., 1991). Furthermore, caecectomy may lead to disturbances in digestion in the upper tract (Sakata, 1987). The intestinal digesta assay is used to measure the digestibility of crude protein (Ravindran et al., 1999; Kadim et al., 2002; Rezvani et al., 2008a, 2008

Received: February 18, 2010, Accepted: May 11, 2010

Released Online Advance Publication: June 25, 2010

Correspondence: Dr. S Hasegawa, Graduate School of Agricultural

Science, Kobe University, Kobe 657-8501, Japan.

(E-mail: hasegawa@kobe-u.ac.jp) b). However, this method needs to sacrifice birds. In addition, the measurement of precaecal amino acid digestibility with digesta sampled from sacrificed animals may be affected by the chosen length of the sampled section (Kluth et al., 2005; Kadim and Moughan, 1997).

Isshiki et al. (1989) established the progressive method of intestinal fistulization in chickens for nutritional study. This method can eliminate the effects of gut microflora in the caecal/colon on the measurement of digestibility, and can be repeated without sacrificing the birds. Using this method, we previously showed that most of the crude protein, crude fat and nitrogen-free extract were absorbed in the middle part of the ileum (MI) when fistulized chickens were fed the formula diet (Kamisoyama et al., 2009, Honda et al., 2009). In birds, there is evidence that the primary site of nutrient absorption is the small intestine (Whittow, 2000). Therefore, this method is useful to determine the digestibility of nutrients in chickens.

Animal fats and vegetable oils are usually used as feed ingredients because fat is not only an important energy source but also a source of essential fatty acids. There is evidence that the differences of dietary fat content affect nutrient digestibility. For example, Mateos and Sell (1980) indicated that supplemental fat enhanced the utilization of energy from dietary carbohydrate in laying hens. Hulan and Bird (1972) reported that the increase of the dietary fat influences the activities of protease, lipase and 
amylase in pancreatic juice. Duke and Evanson (1972) reported that fats are powerful inhibitors of gastric emptying. Recently, we showed that the digestibility of crude protein at the middle part of jejunum (MJ) was decreased in chickens when the birds were fed a high fat diet (Honda et al., 2009). It is therefore likely that dietary fat levels influence the digestibility of amino acids at the MJ in chickens. However, effects of dietary fat levels on amino acid digestibility at the proximal parts of chicken intestines have not yet been investigated.

The objective of the present study was to investigate the effects of dietary fat levels on the digestibilities of amino acids using fistulized chickens.

\section{Materials and Methods}

\section{Birds and Surgical Procedure for Fistulation}

Fifty 250 day-old male Single Comb Whit Leghorn (Ghen Corporation, Gifu, Japan) were used in this study. The birds were assigned to five groups of 10 birds each. Each group was fistulized on either the MJ (at the position of $11 \mathrm{~cm}$ anterior to Meckel's diverticulum), the distal end of the jejunum (DJ, at the position of $2 \mathrm{~cm}$ anterior to Meckel's diverticulum), the MI (at the position of $12 \mathrm{~cm}$ anterior to ileocecoclonic junction), the distal end of the ileum (DI, at the position of $3 \mathrm{~cm}$ anterior to the ileocecoclonic junction) or the distal end of the rectum (DR, at the position of $1 \mathrm{~cm}$ anterior to the cloaca) as described previously (Isshiki et al., 1989). All experimental procedures followed the guidelines for the care and use of experimental animals at the Rokkodai Campus of Kobe University in Japan.

\section{Postoperative Care}

Fistulized birds were placed into individual wire cages and fed commercial diet (CP21\%, ME $285 \mathrm{kcal} / 100 \mathrm{~g}$ diet, Nippon Formula Feed Mfg Co., Ltd. Kanagawa, Japan) and water ad libitum. Birds that showed a decrease in body weight were tube-fed $10 \mathrm{~g}$ of recovery diet (casein $18.00 \%$, glucose $58.02 \%$, corn starch $10.00 \%$, cellulose $2.00 \%$, vitamin mixture $0.20 \%$, mineral mixture $5.63 \%$, choline chloride $0.15 \%$ and aluminum silicate $1.00 \%$ ) for 5 days after operation. Postoperative care and observation were the same as described previously (Isshiki et al., 1989).

\section{Sample Collection}

Fat is often added at levels of 3 to $8 \%$ to increase the dietary energy concentration (Cheeke, 1999). Based on this range, a wider range of fat levels (from 3 to $10 \%$ ) was used in the current study. Birds had free access to water and the experimental diets with various dietary fat levels (Table 1) for 3-days of adaptation period followed by 3days of collection of digesta from each site of intestines. All birds were used repeatedly for all different dietary treatments. As the interval of the dietary treatment, birds were fed the commercial diet for 7 days. Digesta were

Table 1. Composition of experimental diets (g/100 g diet)

\begin{tabular}{lrrrr}
\hline \multirow{2}{*}{\multicolumn{1}{c}{ Ingredients }} & \multicolumn{4}{c}{ Dietary fat level (\%) } \\
\cline { 2 - 5 } & \multicolumn{1}{c}{3} & \multicolumn{1}{c}{5} & \multicolumn{1}{c}{8} & 10 \\
\hline Casein & 15.0 & 15.0 & 15.0 & 15.0 \\
$\alpha$-Corns starch & 10.0 & 10.0 & 10.0 & 10.0 \\
$\beta$-Corn starch & 61.7 & 59.7 & 56.7 & 54.7 \\
Tallow & 3.0 & 5.0 & 8.0 & 10.0 \\
Cellulose & 3.0 & 3.0 & 3.0 & 3.0 \\
Mineral premix ${ }^{1)}$ & 5.6 & 5.6 & 5.6 & 5.6 \\
Vitamin premix ${ }^{2)}$ & 1.2 & 1.2 & 1.2 & 1.2 \\
Chromium oxide & 0.5 & 0.5 & 0.5 & 0.5 \\
\hline Calculated content & & & & \\
Crude protein (\%) & 14.7 & 14.7 & 14.7 & 14.7 \\
Crude fat (\%) & 3.0 & 5.0 & 8.0 & 10.0 \\
Nitrogen free extract(\%) & 74.9 & 72.9 & 69.9 & 67.9 \\
Crude fiber (\%) & 2.2 & 2.2 & 2.2 & 2.2 \\
Crude ash (\%) & 5.2 & 5.2 & 5.2 & 5.2 \\
Metabolizable energy (kcal/g diet) & 2.9 & 2.9 & 3.1 & 3.3 \\
\hline
\end{tabular}

1) Provided the following quantities of microminerals per kilogram of complete diet: $\mathrm{Cu}, 25 \mathrm{mg}$ as copper sulfate; $\mathrm{Fe}, 120 \mathrm{mg}$ as iron sulfate; $\mathrm{I}, 0.30 \mathrm{mg}$ as potassium iodate; $\mathrm{Mn}, 25 \mathrm{mg}$ as manganese sulfate; Se, $0.30 \mathrm{mg}$ as sodium selenite; and $\mathrm{Zn}, 125$ $\mathrm{mg}$ as zinc oxide.

2) Provided the following quantities of vitamins per kilogram of complete diet: vitamin A, 10,032 IU as vitamin A acetate; vitamin D3, 992 IU as D-activated animal sterol; vitamin E, $88 \mathrm{IU}$ as $\alpha$-tocopherol acetate; vitamin $\mathrm{K} 3,1.52 \mathrm{mg}$ as menadione dimethylpyrimidinol bisulphite; thiamin, $1.5 \mathrm{mg}$ as thiamine mononitrate; riboflavin, $10 \mathrm{mg}$; pyridoxine, $4.0 \mathrm{mg}$ as pyridoxine hydrochloride; vitamin B12, $0.05 \mathrm{mg}$; Dpantothenic acid, $25 \mathrm{mg}$ as calcium pantothenate; niacin, $60 \mathrm{mg}$; folic acid, $1.5 \mathrm{mg}$; and biotin, $0.4 \mathrm{mg}$. 
collected at 9: 00 and 17: 00, and samples from each site of intestine were pooled, mixed and dried at $55^{\circ} \mathrm{C}$ for 48 hours.

\section{Chemical Analysis}

Amino acids contents in dried digesta and experimental diets were determined using an amino acids analyzer (Hitachi 835-50, Hitachi Inc., Tokyo, Japan) by the standard methods (AOAC, 1995). For the determination of $\mathrm{Cr}$ concentration, diets and digesta were ashed by a wet-ash digestion with sodium molybdate, sulfuric acid and nitric acid. $\mathrm{Cr}$ concentration was determined at a wavelength of $440 \mathrm{~nm}$ (Bolin et al., 1952).

Apparent digestibility of amino acids was calculated using the $\mathrm{Cr}$ concentration in the diets and digesta at each site of the intestine by using the equation: Apparent digestibility of amino acids $=100-([\mathrm{AAD} / \mathrm{AAF}] \times[\mathrm{CrF} /$ $\mathrm{CrD}] \times 100)$. In this equation, $\mathrm{AAD}$ is the amino acids concentration present in the digesta at each site of the intestine, AAF is the amino acids concentration in the diet (Table 2), $\mathrm{CrF}$ is the $\mathrm{Cr}$ concentration in the diet, and $\mathrm{CrD}$ is the $\mathrm{Cr}$ concentration in the digesta at each site of the intestine. The intestinal digesta contains endogeneous nitrogen including digestive enzymes, mucoproteins, desquamated cells, urea, amino acids produced by cell catabolism, serum albumin and micro-organisms (Rérat, 1978). Therefore, to calculate the true digestibility of amino acids, the amino acids contents in intestinal digesta of chickens fed the protein free diet ( $\alpha$-corn starch $10.0 \%$, corn oil $3.0 \%$, cellulose $3.0 \%$, mineral mix 5.0\%, vitamin mix $1.2 \%, \beta$-corn starch $76.7 \%$, chromium oxide (III) $0.5 \%$ ) are subtracted as endogenous amino acids contents from those of other groups.

\section{Statistical Analysis}

All data were expressed as mean \pm SEM. Data were statistically analyzed by a two-way ANOVA on dietary

Table 2. Amino acid composition of experimental diets

$(\%)$

\begin{tabular}{ccccc}
\hline \hline & \multicolumn{4}{c}{ Dietary fat level $(\%)$} \\
\cline { 2 - 5 } Amino acid & 3 & 5 & 8 & 10 \\
\hline Asp & 1.21 & 1.23 & 1.13 & 1.16 \\
Thr & 0.67 & 0.68 & 0.68 & 0.70 \\
Ser & 0.92 & 0.89 & 0.87 & 0.90 \\
Glu & 3.53 & 3.60 & 3.62 & 3.59 \\
Pro & 1.65 & 1.65 & 1.63 & 1.69 \\
Gly & 0.30 & 0.32 & 0.31 & 0.31 \\
Ala & 0.48 & 0.51 & 0.49 & 0.50 \\
Val & 1.12 & 1.10 & 1.07 & 1.09 \\
Met & 0.33 & 0.37 & 0.35 & 0.33 \\
Ile & 0.76 & 0.81 & 0.77 & 0.78 \\
Leu & 1.38 & 1.48 & 1.43 & 1.46 \\
Tyr & 0.76 & 0.72 & 0.79 & 0.79 \\
Phe & 0.77 & 0.78 & 0.80 & 0.81 \\
Lys & 1.29 & 1.27 & 1.26 & 1.30 \\
His & 0.52 & 0.49 & 0.48 & 0.48 \\
Arg & 0.62 & 59.00 & 0.57 & 0.58 \\
\hline
\end{tabular}

treatments and sites of digestive tract. Dunnett's post hoc test was then performed using the values at the MJ (Tables 4-7) or the 3\% group (Tables $8-12$ ) as the control. Significant difference was set at $P<0.05$. All statistical analyses were performed using the commercial package (StatView version 5, SAS Institute, Cary, NC, USA, 1998).

\section{Results}

In this study, there was no significant difference in food intake between groups (data not shown). Table 3 shows that the total amino acids contents in intestinal digesta tended to increase at the ileum and the rectum in the protein free diet group. These values were used for the calculation of the true digestibilities of amino acids. There was no significant interaction between dietary treatments and sites of intestine (data not shown).

As shown in Tables 4-6, true digestibility of individual amino acids was not affected by the sites of intestines in the 3, 5 and $8 \%$ fat groups. It ranged from $84-100 \%$ for individual amino acids without significant differences. The true digestibility of total amino acid in intestinal digesta at the MJ was significantly lower than that at the DJ in the $10 \%$ fat group (Table 7 ). In addition, true digestibilities of individual amino acids at the MJ tended to be lower than those at the DJ in the $10 \%$ fat group (Table 7).

Comparison of the values at each site of the intestine in Tables 4-7 was shown in Tables 8-12. The true digestibilities of total amino acid and Met in intestinal digesta in the $10 \%$ fat group were significantly lower than those in other groups (Table 8). The true digestibilities of all amino acids, except for Met, in intestinal digesta at the $\mathrm{MJ}$ in the $10 \%$ fat group tended to be lower than those in other groups (Table 8). There was no significant difference in the true digestibilities of amino acids at the DJ, MI, DI and DR among the groups (Tables 9-12).

\section{Discussion}

The true digestibility of most amino acids in intestinal digesta at the DJ reached more than $90 \%$ in all groups, and there was no significant difference between the DJ and the DR (Table 4-7). Rezvani et al. (2008a) reported that the net digestibility of all studied amino acid in both soybean meal and rapeseed meal was significantly lower in the proximal sub-section of the ileum than that in the central or terminal sub-sections of the ileum. We recently showed that the digestibility of crude protein was decreased at the MJ in chickens when the birds were fed a high fat diet (Honda et al., 2009). These findings suggest that the primary site for amino acid absorption is the jejunum in chickens.

Yokota and Tasaki (1970) investigated the sites and the rates of intestinal absorption of various amino acids in chicken intestine in situ. They showed that Met and Ala were absorbed more slowly from the duodenum and the jejunum than from the ileum. The absorption rate of Phe 
Table 3. The amount of amino acids at different sites of the digestive tract of chickens fed a protein free diet

\begin{tabular}{crrrrr}
\hline \hline & \multicolumn{1}{c}{ MJ } & \multicolumn{1}{c}{ DJ } & \multicolumn{1}{c}{ MI } & \multicolumn{1}{c}{ DI } & DR \\
\hline Asp & $35.14 \pm 8.25$ & $46.19 \pm 6.66$ & $48.60 \pm 3.10$ & $46.12 \pm 3.13$ & $64.91 \pm 4.41$ \\
Thr & $30.14 \pm 2.24$ & $37.29 \pm 9.44$ & $43.48 \pm 3.25$ & $35.12 \pm 6.12$ & $51.04 \pm 3.93$ \\
Ser & $23.03 \pm 8.44$ & $29.16 \pm 9.08$ & $40.41 \pm 8.02$ & $31.26 \pm 7.91$ & $50.38 \pm 6.60$ \\
Glu & $44.08 \pm 6.60$ & $51.41 \pm 5.13$ & $65.34 \pm 7.31$ & $56.57 \pm 6.87$ & $73.49 \pm 8.29$ \\
Pro & $20.53 \pm 1.99$ & $24.25 \pm 1.59$ & $40.00 \pm 4.74$ & $31.59 \pm 1.96$ & $51.59 \pm 6.28$ \\
Gly & $20.17 \pm 1.59$ & $26.08 \pm 9.28$ & $30.62 \pm 1.56$ & $29.34 \pm 2.75$ & $43.21 \pm 8.74$ \\
Ala & $24.45 \pm 4.72$ & $29.94 \pm 2.77$ & $29.10 \pm 2.23$ & $29.95 \pm 3.85$ & $38.37 \pm 2.45$ \\
Val & $34.28 \pm 1.01$ & $28.11 \pm 6.38$ & $30.08 \pm 9.57$ & $43.99 \pm 8.59$ & $59.86 \pm 9.35$ \\
Met & $4.56 \pm 5.64$ & $4.80 \pm 2.48$ & $7.35 \pm 7.70$ & $9.08 \pm 7.05$ & $11.54 \pm 5.11$ \\
Ile & $19.31 \pm 3.94$ & $23.36 \pm 2.96$ & $29.41 \pm 6.17$ & $26.89 \pm 5.70$ & $39.28 \pm 6.94$ \\
Leu & $27.46 \pm 2.58$ & $31.18 \pm 2.29$ & $42.18 \pm 1.38$ & $35.49 \pm 1.71$ & $50.69 \pm 0.60$ \\
Tyr & $12.50 \pm 6.67$ & $14.16 \pm 7.69$ & $16.63 \pm 7.26$ & $15.13 \pm 7.65$ & $21.64 \pm 5.68$ \\
Phe & $15.46 \pm 9.25$ & $17.14 \pm 6.60$ & $22.29 \pm 4.22$ & $19.77 \pm 9.36$ & $30.04 \pm 4.52$ \\
Lys & $13.16 \pm 4.81$ & $15.02 \pm 5.18$ & $9.91 \pm 6.28$ & $12.51 \pm 9.02$ & $15.30 \pm 3.36$ \\
His & $7.48 \pm 9.51$ & $10.33 \pm 7.00$ & $8.86 \pm 2.34$ & $9.38 \pm 8.60$ & $11.85 \pm 5.59$ \\
Arg & $16.81 \pm 5.59$ & $20.86 \pm 9.17$ & $25.85 \pm 4.18$ & $19.77 \pm 0.91$ & $29.01 \pm 3.70$ \\
Total & $348.54 \pm 38.06$ & $409.28 \pm 40.37$ & $490.12 \pm 28.04$ & $451.96 \pm 31.86$ & $642.19 \pm 50.07$ \\
\hline
\end{tabular}

Data represent the mean \pm SEM of 10 birds.

MJ: the middle part of the jejunum, DJ: the distal end of the jejunum, MI: the middle part of the ileum, DI: the distal end of the ileum, DR: the distal end of the rectum.

Table 4. True digestibility of amino acid at different sites of chicken intestines in the $3 \%$ fat group

\begin{tabular}{|c|c|c|c|c|c|}
\hline \multirow{2}{*}{ Amino acid } & \multicolumn{5}{|c|}{ Site of intestine } \\
\hline & MJ & DJ & MI & DI & $\mathrm{DR}$ \\
\hline Asp & $93.45 \pm 6.71$ & $93.35 \pm 8.33$ & $91.96 \pm 8.26$ & $96.09 \pm 7.72$ & $96.58 \pm 3.58$ \\
\hline Thr & $92.64 \pm 6.72$ & $91.35 \pm 4.28$ & $87.21 \pm 3.55$ & $94.68 \pm 2.57$ & $96.77 \pm 7.61$ \\
\hline Ser & $84.44 \pm 8.97$ & $85.81 \pm 11.08$ & $81.13 \pm 8.35$ & $85.60 \pm 4.41$ & $88.28 \pm 6.59$ \\
\hline Glu & $91.63 \pm 2.10$ & $92.92 \pm 10.30$ & $93.07 \pm 3.69$ & $93.90 \pm 7.26$ & $95.02 \pm 4.29$ \\
\hline Pro & $96.53 \pm 6.10$ & $96.60 \pm 6.80$ & $93.95 \pm 5.08$ & $98.08 \pm 7.03$ & $98.86 \pm 5.25$ \\
\hline Gly & $95.57 \pm 9.19$ & $91.03 \pm 5.17$ & $82.43 \pm 7.75$ & $95.66 \pm 7.04$ & $95.66 \pm 3.54$ \\
\hline Ala & $92.10 \pm 9.94$ & $94.06 \pm 2.74$ & $89.40 \pm 8.46$ & $94.76 \pm 6.93$ & $94.38 \pm 6.87$ \\
\hline Val & $96.07 \pm 9.54$ & $95.32 \pm 5.84$ & $92.97 \pm 4.10$ & $95.60 \pm 5.17$ & $97.26 \pm 7.28$ \\
\hline Met & $97.88 \pm 3.42$ & $98.56 \pm 2.65$ & $96.77 \pm 6.72$ & $97.33 \pm 4.04$ & $98.37 \pm 5.33$ \\
\hline Ile & $91.54 \pm 5.70$ & $92.58 \pm 7.54$ & $90.39 \pm 2.27$ & $92.61 \pm 8.74$ & $93.32 \pm 3.96$ \\
\hline Leu & $98.70 \pm 5.46$ & $98.20 \pm 4.25$ & $96.07 \pm 2.90$ & $99.19 \pm 7.21$ & $99.15 \pm 6.02$ \\
\hline Tyr & $99.13 \pm 1.58$ & $98.19 \pm 2.30$ & $96.90 \pm 8.78$ & $99.09 \pm 7.07$ & $98.66 \pm 5.48$ \\
\hline Phe & $99.10 \pm 7.27$ & $98.15 \pm 3.03$ & $96.01 \pm 6.78$ & $99.84 \pm 9.66$ & $99.40 \pm 8.19$ \\
\hline Lys & $97.12 \pm 4.98$ & $98.37 \pm 2.04$ & $97.62 \pm 9.22$ & $98.27 \pm 6.56$ & $98.23 \pm 8.09$ \\
\hline His & $96.02 \pm 7.78$ & $97.31 \pm 4.88$ & $97.26 \pm 4.57$ & $98.43 \pm 8.30$ & $98.37 \pm 7.57$ \\
\hline Arg & $99.28 \pm 2.42$ & $97.12 \pm 3.63$ & $92.12 \pm 6.56$ & $99.54 \pm 2.86$ & $99.30 \pm 2.79$ \\
\hline Total & $95.08 \pm 2.81$ & $94.93 \pm 5.06$ & $92.20 \pm 4.63$ & $96.17 \pm 7.26$ & $96.73 \pm 4.94$ \\
\hline
\end{tabular}

Data represent the mean \pm SEM of 10 birds.

MJ: the middle part of the jejunum, DJ: the distal end of the jejunum, MI: the middle part of the ileum, DI: the distal end of the ileum, DR: the distal end of the rectum.

had a trend to increase progressively from the duodenum to the lower ileum. A basic amino acid Lys was absorbed more rapidly from the jejunum and the ileum than from the duodenum. An acidic amino acid Glu was rapidly absorbed from the upper jejunum and the lower ileum than from the other segments. However, in the present study, the true digestibilities of most amino acids were higher than $90 \%$ at the DJ. It seems likely that the proximal part of the jejunum is the important site of amino acid absorption in chickens in vivo, although several amino acids can be absorbed actively throughout the intestinal tract.

There is evidence that amino acid digestibility is affected by different dietary protein sources. For example, Kadim 
Table 5. True digestibility of amino acid at different sites of chicken intestines in the $\mathbf{5} \%$ fat group

\begin{tabular}{cccccc}
\hline \hline \multirow{2}{*}{ Amino acid } & \multicolumn{5}{c}{ Site of intestine } \\
\cline { 2 - 6 } & MJ & DJ & MI & DI & DR \\
\hline Asp & $91.80 \pm 6.49$ & $89.09 \pm 4.73$ & $95.72 \pm 4.10$ & $97.19 \pm 7.32$ & $96.82 \pm 6.37$ \\
Thr & $90.58 \pm 10.62$ & $90.40 \pm 8.29$ & $93.02 \pm 6.32$ & $96.86 \pm 7.76$ & $97.08 \pm 8.04$ \\
Ser & $85.44 \pm 9.69$ & $84.92 \pm 7.31$ & $89.03 \pm 9.46$ & $88.13 \pm 3.99$ & $88.69 \pm 9.39$ \\
Glu & $90.07 \pm 7.79$ & $89.22 \pm 6.01$ & $94.90 \pm 9.31$ & $94.85 \pm 6.96$ & $95.39 \pm 7.40$ \\
Pro & $93.88 \pm 5.54$ & $93.18 \pm 3.28$ & $97.84 \pm 5.44$ & $98.72 \pm 8.59$ & $99.15 \pm 4.39$ \\
Gly & $93.10 \pm 2.34$ & $88.92 \pm 3.64$ & $94.88 \pm 8.46$ & $90.71 \pm 7.61$ & $90.71 \pm 8.26$ \\
Ala & $91.92 \pm 4.45$ & $88.63 \pm 6.17$ & $95.49 \pm 8.07$ & $95.92 \pm 7.91$ & $95.42 \pm 7.74$ \\
Val & $94.08 \pm 2.21$ & $91.53 \pm 3.84$ & $97.66 \pm 4.05$ & $96.37 \pm 7.99$ & $97.77 \pm 5.45$ \\
Met & $95.11 \pm 9.81$ & $92.23 \pm 8.54$ & $97.23 \pm 9.88$ & $97.53 \pm 9.26$ & $97.78 \pm 3.82$ \\
Ile & $90.02 \pm 4.10$ & $87.77 \pm 7.51$ & $94.57 \pm 6.69$ & $93.75 \pm 2.98$ & $94.00 \pm 6.59$ \\
Leu & $96.66 \pm 7.79$ & $94.30 \pm 9.09$ & $99.38 \pm 2.99$ & $99.52 \pm 7.94$ & $99.11 \pm 8.69$ \\
Tyr & $97.07 \pm 9.34$ & $94.99 \pm 8.54$ & $98.51 \pm 2.47$ & $99.18 \pm 9.86$ & $98.82 \pm 7.27$ \\
Phe & $96.74 \pm 1.65$ & $94.41 \pm 9.66$ & $99.51 \pm 7.30$ & $99.83 \pm 2.48$ & $99.32 \pm 2.44$ \\
Lys & $95.99 \pm 4.69$ & $93.83 \pm 8.54$ & $88.25 \pm 8.46$ & $98.29 \pm 7.83$ & $97.80 \pm 3.81$ \\
His & $95.51 \pm 7.61$ & $94.01 \pm 5.74$ & $98.82 \pm 5.34$ & $99.20 \pm 8.43$ & $98.54 \pm 6.29$ \\
Arg & $97.86 \pm 2.75$ & $93.87 \pm 5.33$ & $98.92 \pm 7.35$ & $99.76 \pm 5.01$ & $99.58 \pm 3.77$ \\
Total & $93.49 \pm 11.22$ & $91.33 \pm 5.91$ & $95.86 \pm 8.39$ & $96.61 \pm 4.80$ & $96.62 \pm 11.81$ \\
\hline
\end{tabular}

Data represent the mean \pm SEM of 10 birds.

MJ: the middle part of the jejunum, DJ: the distal end of the jejunum, MI: the middle part of the ileum, DI: the distal end of the ileum, DR: the distal end of the rectum.

Table 6. True digestibility of amino acid at different sites of chicken intestines in the $8 \%$ fat group

\begin{tabular}{|c|c|c|c|c|c|}
\hline \multirow{2}{*}{ Amino acid } & \multicolumn{5}{|c|}{ Site of intestine } \\
\hline & MJ & DJ & MI & DI & DR \\
\hline Asp & $95.18 \pm 7.13$ & $97.14 \pm 3.14$ & $97.11 \pm 4.20$ & $98.45 \pm 5.71$ & $97.73 \pm 2.91$ \\
\hline Thr & $94.83 \pm 7.71$ & $94.57 \pm 5.72$ & $95.20 \pm 6.01$ & $97.73 \pm 4.78$ & $97.42 \pm 2.05$ \\
\hline Ser & $91.88 \pm 8.43$ & $94.23 \pm 4.06$ & $91.86 \pm 9.46$ & $91.74 \pm 10.30$ & $94.09 \pm 3.33$ \\
\hline Glu & $91.73 \pm 5.41$ & $95.40 \pm 6.09$ & $95.96 \pm 6.30$ & $96.12 \pm 2.52$ & $96.27 \pm 3.36$ \\
\hline Pro & $94.18 \pm 9.17$ & $99.24 \pm 5.78$ & $98.16 \pm 4.74$ & $99.36 \pm 1.41$ & $99.00 \pm 1.39$ \\
\hline Gly & $97.33 \pm 3.60$ & $97.76 \pm 8.06$ & $96.29 \pm 5.99$ & $98.03 \pm 3.08$ & $98.03 \pm 2.67$ \\
\hline Ala & $97.23 \pm 2.43$ & $97.93 \pm 7.24$ & $96.68 \pm 5.11$ & $98.13 \pm 2.75$ & $97.08 \pm 2.35$ \\
\hline Val & $95.96 \pm 2.86$ & $98.38 \pm 1.86$ & $98.37 \pm 5.94$ & $97.34 \pm 2.88$ & $98.24 \pm 1.18$ \\
\hline Met & $94.38 \pm 3.03$ & $99.95 \pm 2.02$ & $99.06 \pm 2.69$ & $97.56 \pm 5.63$ & $96.96 \pm 4.83$ \\
\hline Ile & $93.74 \pm 4.52$ & $95.85 \pm 4.96$ & $95.78 \pm 4.06$ & $95.61 \pm 7.57$ & $94.15 \pm 4.84$ \\
\hline Leu & $98.16 \pm 4.49$ & $98.18 \pm 2.31$ & $99.53 \pm 2.96$ & $98.24 \pm 4.26$ & $99.32 \pm 2.96$ \\
\hline Tyr & $96.24 \pm 2.93$ & $99.02 \pm 7.85$ & $99.04 \pm 3.59$ & $99.36 \pm 1.43$ & $98.94 \pm 3.79$ \\
\hline Phe & $98.02 \pm 1.60$ & $99.95 \pm 7.27$ & $99.77 \pm 1.06$ & $99.65 \pm 1.27$ & $99.66 \pm 0.92$ \\
\hline Lys & $97.00 \pm 2.50$ & $99.30 \pm 8.06$ & $98.61 \pm 4.23$ & $98.99 \pm 4.43$ & $98.57 \pm 1.95$ \\
\hline His & $96.30 \pm 6.97$ & $99.30 \pm 3.09$ & $99.10 \pm 2.12$ & $99.58 \pm 1.40$ & $98.97 \pm 2.10$ \\
\hline Arg & $99.58 \pm 1.54$ & $98.98 \pm 3.58$ & $99.03 \pm 1.15$ & $99.44 \pm 2.72$ & $99.66 \pm 2.23$ \\
\hline Total & $95.73 \pm 8.51$ & $97.82 \pm 7.30$ & $97.47 \pm 6.97$ & $97.83 \pm 4.70$ & $97.76 \pm 2.65$ \\
\hline
\end{tabular}

Data represent the mean \pm SEM of 10 birds.

MJ: the middle part of the jejunum, DJ: the distal end of the jejunum, MI: the middle part of the ileum, DI: the distal end of the ileum, DR: the distal end of the rectum.

et al. (2002) reported that the range for overall true ileal amino acid digestibility was $63.2 \%$ for blood meal to $96.5 \%$ for sorghum in broiler chickens. Adedokun et al. (2008) reported that the range for overall true ileal amino acid digestibility was $\mathbf{7 2 . 8 \%}$ for dark corn distillers dried grains with solubles to $91.0 \%$ for corn in broiler chickens.
In the present study, the true digestibility of total amino acid at the DI in all groups was more than 95.9\% (Table $11)$, suggesting that casein is one of the highly digestible proteins. Amino acid digestibility is also affected by the class of chickens. For example, the digestibility of amino acids in soybean meal is higher for layers compared with 
Table 7. True digestibility of amino acid at different sites of chicken intestines in the $10 \%$ fat group

\begin{tabular}{cccccc}
\hline \hline & \multicolumn{5}{c}{ Site of intestine } \\
Amino acid & MJ & DJ & MI & DI & DR \\
\cline { 2 - 6 } & $84.14 \pm 9.81$ & $96.93 \pm 11.73$ & $95.31 \pm 11.87$ & $97.36 \pm 11.47$ & $95.79 \pm 6.14$ \\
Asp & $85.37 \pm 10.86$ & $94.23 \pm 10.29$ & $93.43 \pm 7.23$ & $96.21 \pm 3.66$ & $96.76 \pm 8.90$ \\
Thr & $91.74 \pm 2.31$ & $93.30 \pm 3.07$ & $89.32 \pm 11.65$ & $91.89 \pm 7.98$ & $94.89 \pm 5.52$ \\
Ser & $83.88 \pm 9.62$ & $95.74 \pm 8.59$ & $95.26 \pm 10.85$ & $96.40 \pm 2.11$ & $95.59 \pm 4.90$ \\
Glu & $87.28 \pm 7.33$ & $98.76 \pm 8.58$ & $97.12 \pm 7.17$ & $99.00 \pm 9.97$ & $98.98 \pm 7.67$ \\
Pro & $84.01 \pm 3.88$ & $96.33 \pm 5.85$ & $91.83 \pm 3.81$ & $91.55 \pm 9.52$ & $91.55 \pm 10.21$ \\
Gly & $83.82 \pm 4.46$ & $96.93 \pm 4.39$ & $93.98 \pm 11.72$ & $97.27 \pm 8.53$ & $93.97 \pm 2.07$ \\
Ala & $87.23 \pm 8.20$ & $97.61 \pm 10.98$ & $96.81 \pm 3.63$ & $96.81 \pm 8.62$ & $96.40 \pm 9.87$ \\
Val & $85.18 \pm 7.37$ & $96.66 \pm 6.41$ & $99.32 \pm 3.54$ & $97.84 \pm 6.59$ & $97.18 \pm 4.92$ \\
Met & $83.78 \pm 8.53$ & $94.72 \pm 7.47$ & $94.37 \pm 5.76$ & $94.58 \pm 10.81$ & $97.07 \pm 4.19$ \\
Ile & $92.08 \pm 9.33$ & $99.26 \pm 7.37$ & $98.49 \pm 2.37$ & $99.40 \pm 6.85$ & $98.84 \pm 8.16$ \\
Leu & $94.55 \pm 3.54$ & $98.92 \pm 6.37$ & $98.41 \pm 6.71$ & $98.63 \pm 9.73$ & $98.05 \pm 4.24$ \\
Tyr & $92.54 \pm 7.99$ & $99.22 \pm 9.75$ & $98.48 \pm 11.90$ & $99.68 \pm 4.66$ & $98.69 \pm 3.32$ \\
Phe & $92.64 \pm 4.94$ & $99.17 \pm 8.78$ & $98.06 \pm 10.11$ & $98.79 \pm 6.07$ & $97.69 \pm 5.70$ \\
Lys & $89.81 \pm 4.84$ & $98.94 \pm 2.02$ & $98.44 \pm 3.16$ & $98.28 \pm 3.91$ & $98.05 \pm 2.62$ \\
His & $92.73 \pm 7.29$ & $99.93 \pm 6.76$ & $97.22 \pm 10.51$ & $99.42 \pm 4.46$ & $98.07 \pm 3.26$ \\
Arg & $88.17 \pm 2.41$ & $97.29 \pm 4.41^{*}$ & $95.99 \pm 6.09$ & $97.07 \pm 2.25 *$ & $96.72 \pm 2.10^{*}$ \\
Total & & & & & \\
\hline
\end{tabular}

Data represent the mean \pm SEM of 10 birds.

*, significant with respect to the MJ $(P<0.05)$.

MJ: the middle part of the jejunum, DJ: the distal end of the jejunum, MI: the middle part of the ileum, DI: the distal end of the ileum, DR: the distal end of the rectum.

Table 8. Comparison of the true digestibility of amino acids at the middle part of the jejunum between groups

$(\%)$

\begin{tabular}{ccccc}
\hline \hline \multirow{2}{*}{ Amino acid } & \multicolumn{4}{c}{ Dietary fat level $(\%)$} \\
\cline { 2 - 5 } & 3 & 5 & 8 & 10 \\
\hline Asp & $93.45 \pm 6.71$ & $91.80 \pm 6.49$ & $95.18 \pm 7.13$ & $84.14 \pm 9.81$ \\
Thr & $92.64 \pm 6.72$ & $90.58 \pm 10.62$ & $94.83 \pm 7.71$ & $85.37 \pm 10.86$ \\
Ser & $84.44 \pm 8.97$ & $85.44 \pm 9.69$ & $91.88 \pm 8.43$ & $91.74 \pm 2.31$ \\
Glu & $91.63 \pm 2.10$ & $90.07 \pm 7.79$ & $91.73 \pm 5.41$ & $83.88 \pm 9.62$ \\
Pro & $96.53 \pm 6.10$ & $93.88 \pm 5.54$ & $94.18 \pm 9.17$ & $87.28 \pm 7.33$ \\
Gly & $95.57 \pm 9.19$ & $93.10 \pm 2.34$ & $97.33 \pm 3.60$ & $84.01 \pm 3.88$ \\
Ala & $92.10 \pm 9.94$ & $91.92 \pm 4.45$ & $97.23 \pm 2.43$ & $83.82 \pm 4.46$ \\
Val & $96.07 \pm 9.54$ & $94.08 \pm 2.21$ & $95.96 \pm 2.86$ & $87.23 \pm 8.20$ \\
Met & $97.88 \pm 3.42$ & $95.11 \pm 9.81$ & $94.38 \pm 3.03$ & $85.18 \pm 7.37 *$ \\
Ile & $91.54 \pm 5.70$ & $90.02 \pm 4.10$ & $93.74 \pm 4.52$ & $83.78 \pm 8.53$ \\
Leu & $98.70 \pm 5.46$ & $96.66 \pm 7.79$ & $98.16 \pm 4.49$ & $92.08 \pm 9.33$ \\
Tyr & $99.13 \pm 1.58$ & $97.07 \pm 9.34$ & $96.24 \pm 2.93$ & $94.55 \pm 3.54$ \\
Phe & $99.10 \pm 7.27$ & $96.74 \pm 1.65$ & $98.02 \pm 1.60$ & $92.54 \pm 7.99$ \\
Lys & $97.12 \pm 4.98$ & $95.99 \pm 4.69$ & $97.00 \pm 2.50$ & $92.64 \pm 4.94$ \\
His & $96.02 \pm 7.78$ & $95.51 \pm 7.61$ & $96.30 \pm 6.97$ & $89.81 \pm 4.84$ \\
Arg & $99.28 \pm 2.42$ & $97.86 \pm 2.75$ & $99.58 \pm 1.54$ & $92.73 \pm 7.29$ \\
Total & $95.08 \pm 2.81$ & $93.49 \pm 11.22$ & $95.73 \pm 8.51$ & $88.17 \pm 2.41^{*}$ \\
\hline
\end{tabular}

Data represent the mean \pm SEM of 10 birds.

*, significant with respect to the $3 \%$ fat group $(P<0.05)$.

that for broilers, whereas the digestibility of amino acids for wheat, corn and sorghum is lower in layers than that in broilers (Huang et al., 2006). However, casein is also estimated as a highly digestible protein in broiler study (Adedokun et al., 2007). These findings and our results suggest that casein is one of the highly digestible proteins in both layers and broilers.

In this study, the true digestibility of total amino acid in intestinal digesta at the MJ was significantly lower in the $10 \%$ fat group (Table 8 ). We previously showed that the true digestibility of $\mathrm{CP}$ in intestinal digesta was significantly lower at the $\mathrm{MJ}$ in chickens when the birds 
Table 9. Comparison of the true digestibility of amino acids at the distal end of the jejunum between groups

\begin{tabular}{ccccc}
\hline \hline & & \multicolumn{2}{c}{ Dietary fat level $(\%)$} & 10 \\
\cline { 2 - 5 } Amino acid & 3 & 5 & 8 & $84.14 \pm 9.81$ \\
\cline { 2 - 5 } Asp & $93.45 \pm 6.71$ & $91.80 \pm 6.49$ & $95.18 \pm 7.13$ & $85.37 \pm 10.86$ \\
Thr & $92.64 \pm 6.72$ & $90.58 \pm 10.62$ & $94.83 \pm 7.71$ & $91.74 \pm 2.31$ \\
Ser & $84.44 \pm 8.97$ & $85.44 \pm 9.69$ & $91.88 \pm 8.43$ & $83.88 \pm 9.62$ \\
Glu & $91.63 \pm 2.10$ & $90.07 \pm 7.79$ & $91.73 \pm 5.41$ & $87.28 \pm 7.33$ \\
Pro & $96.53 \pm 6.10$ & $93.88 \pm 5.54$ & $94.18 \pm 9.17$ & $84.01 \pm 3.88$ \\
Gly & $95.57 \pm 9.19$ & $93.10 \pm 2.34$ & $97.33 \pm 3.60$ & $83.82 \pm 4.46$ \\
Ala & $92.10 \pm 9.94$ & $91.92 \pm 4.45$ & $97.23 \pm 2.43$ & $87.23 \pm 8.20$ \\
Val & $96.07 \pm 9.54$ & $94.08 \pm 2.21$ & $95.96 \pm 2.86$ & $85.18 \pm 7.37$ \\
Met & $97.88 \pm 3.42$ & $95.11 \pm 9.81$ & $94.38 \pm 3.03$ & $83.78 \pm 8.53$ \\
Ile & $91.54 \pm 5.70$ & $90.02 \pm 4.10$ & $93.74 \pm 4.52$ & $92.08 \pm 9.33$ \\
Leu & $98.70 \pm 5.46$ & $96.66 \pm 7.79$ & $98.16 \pm 4.49$ & $94.55 \pm 3.54$ \\
Tyr & $99.13 \pm 1.58$ & $97.07 \pm 9.34$ & $96.24 \pm 2.93$ & $92.54 \pm 7.99$ \\
Phe & $99.10 \pm 7.27$ & $96.74 \pm 1.65$ & $98.02 \pm 1.60$ & $92.64 \pm 4.94$ \\
Lys & $97.12 \pm 4.98$ & $95.99 \pm 4.69$ & $97.00 \pm 2.50$ & $89.81 \pm 4.84$ \\
His & $96.02 \pm 7.78$ & $95.51 \pm 7.61$ & $96.30 \pm 6.97$ & $92.73 \pm 7.29$ \\
Arg & $99.28 \pm 2.42$ & $97.86 \pm 2.75$ & $99.58 \pm 1.54$ & $88.17 \pm 2.41$ \\
Total & $95.08 \pm 2.81$ & $93.49 \pm 11.22$ & $95.73 \pm 8.51$ & \\
\hline
\end{tabular}

Data represent the mean \pm SEM of 10 birds.

Table 10. Comparison of the true digestibility of amino acids at the middle part of the ileum between groups

\begin{tabular}{ccccc}
\hline \hline \multirow{2}{*}{ Amino acid } & \multicolumn{4}{c}{ Dietary fat level $(\%)$} \\
\cline { 2 - 5 } & 3 & 5 & 8 & 10 \\
\hline Asp & $93.45 \pm 6.71$ & $91.80 \pm 6.49$ & $95.18 \pm 7.13$ & $84.14 \pm 9.81$ \\
Thr & $92.64 \pm 6.72$ & $90.58 \pm 10.62$ & $94.83 \pm 7.71$ & $85.37 \pm 10.86$ \\
Ser & $84.44 \pm 8.97$ & $85.44 \pm 9.69$ & $91.88 \pm 8.43$ & $91.74 \pm 2.31$ \\
Glu & $91.63 \pm 2.10$ & $90.07 \pm 7.79$ & $91.73 \pm 5.41$ & $83.88 \pm 9.62$ \\
Pro & $96.53 \pm 6.10$ & $93.88 \pm 5.54$ & $94.18 \pm 9.17$ & $87.28 \pm 7.33$ \\
Gly & $95.57 \pm 9.19$ & $93.10 \pm 2.34$ & $97.33 \pm 3.60$ & $84.01 \pm 3.88$ \\
Ala & $92.10 \pm 9.94$ & $91.92 \pm 4.45$ & $97.23 \pm 2.43$ & $83.82 \pm 4.46$ \\
Val & $96.07 \pm 9.54$ & $94.08 \pm 2.21$ & $95.96 \pm 2.86$ & $87.23 \pm 8.20$ \\
Met & $97.88 \pm 3.42$ & $95.11 \pm 9.81$ & $94.38 \pm 3.03$ & $85.18 \pm 7.37$ \\
Ile & $91.54 \pm 5.70$ & $90.02 \pm 4.10$ & $93.74 \pm 4.52$ & $83.78 \pm 8.53$ \\
Leu & $98.70 \pm 5.46$ & $96.66 \pm 7.79$ & $98.16 \pm 4.49$ & $92.08 \pm 9.33$ \\
Tyr & $99.13 \pm 1.58$ & $97.07 \pm 9.34$ & $96.24 \pm 2.93$ & $94.55 \pm 3.54$ \\
Phe & $99.10 \pm 7.27$ & $96.74 \pm 1.65$ & $98.02 \pm 1.60$ & $92.54 \pm 7.99$ \\
Lys & $97.12 \pm 4.98$ & $95.99 \pm 4.69$ & $97.00 \pm 2.50$ & $92.64 \pm 4.94$ \\
His & $96.02 \pm 7.78$ & $95.51 \pm 7.61$ & $96.30 \pm 6.97$ & $89.81 \pm 4.84$ \\
Arg & $99.28 \pm 2.42$ & $97.86 \pm 2.75$ & $99.58 \pm 1.54$ & $92.73 \pm 7.29$ \\
Total & $95.08 \pm 2.81$ & $93.49 \pm 11.22$ & $95.73 \pm 8.51$ & $88.17 \pm 2.41$ \\
\hline
\end{tabular}

Data represent the mean \pm SEM of 10 birds.

were fed the 10\% fat diet (Honda et al., 2009). Hulan and Bird (1972) reported that high fat diet feeding tends to lower the protease activity in pancreatic juice. Physicochemical changes in intestinal digesta might also influence amino acid digestibility in the $10 \%$ fat group. For example, there is evidence that an increase in digesta viscosity might reduce the diffusion rate of digestive enzymes such as protease (Larsen et al., 1993). The underlying mechanisms and reasons still require clarification.
However, it is possible that the lowered digestibility of amino acids at the MJ in the $10 \%$ fat group is due to insufficient digestion by pancreatic protease. Further studies will be needed to investigate the effects of dietary fat levels on the pancreatic protease activity in chickens.

The overall level of amino acid digestibility at the $\mathrm{MJ}$ in the $3 \%$ fat group (Table 4, 84-100\%) was higher than that in the previous study (Kamisoyama et al., 2010, 77$94 \%$ ), and the range in amino acid digestibility at the DJ 
Table 11. Comparison of the true digestibility of amino acids at the distal end of the ileum between groups

\begin{tabular}{ccccc}
\hline \hline \multirow{2}{*}{ Amino acid } & \multicolumn{4}{c}{ Dietary fat level $(\%)$} \\
\cline { 2 - 5 } & 3 & 5 & 8 & 10 \\
\hline Asp & $93.45 \pm 6.71$ & $91.80 \pm 6.49$ & $95.18 \pm 7.13$ & $84.14 \pm 9.81$ \\
Thr & $92.64 \pm 6.72$ & $90.58 \pm 10.62$ & $94.83 \pm 7.71$ & $85.37 \pm 10.86$ \\
Ser & $84.44 \pm 8.97$ & $85.44 \pm 9.69$ & $91.88 \pm 8.43$ & $91.74 \pm 2.31$ \\
Glu & $91.63 \pm 2.10$ & $90.07 \pm 7.79$ & $91.73 \pm 5.41$ & $83.88 \pm 9.62$ \\
Pro & $96.53 \pm 6.10$ & $93.88 \pm 5.54$ & $94.18 \pm 9.17$ & $87.28 \pm 7.33$ \\
Gly & $95.57 \pm 9.19$ & $93.10 \pm 2.34$ & $97.33 \pm 3.60$ & $84.01 \pm 3.88$ \\
Ala & $92.10 \pm 9.94$ & $91.92 \pm 4.45$ & $97.23 \pm 2.43$ & $83.82 \pm 4.46$ \\
Val & $96.07 \pm 9.54$ & $94.08 \pm 2.21$ & $95.96 \pm 2.86$ & $87.23 \pm 8.20$ \\
Met & $97.88 \pm 3.42$ & $95.11 \pm 9.81$ & $94.38 \pm 3.03$ & $85.18 \pm 7.37$ \\
Ile & $91.54 \pm 5.70$ & $90.02 \pm 4.10$ & $93.74 \pm 4.52$ & $83.78 \pm 8.53$ \\
Leu & $98.70 \pm 5.46$ & $96.66 \pm 7.79$ & $98.16 \pm 4.49$ & $92.08 \pm 9.33$ \\
Tyr & $99.13 \pm 1.58$ & $97.07 \pm 9.34$ & $96.24 \pm 2.93$ & $94.55 \pm 3.54$ \\
Phe & $99.10 \pm 7.27$ & $96.74 \pm 1.65$ & $98.02 \pm 1.60$ & $92.54 \pm 7.99$ \\
Lys & $97.12 \pm 4.98$ & $95.99 \pm 4.69$ & $97.00 \pm 2.50$ & $92.64 \pm 4.94$ \\
His & $96.02 \pm 7.78$ & $95.51 \pm 7.61$ & $96.30 \pm 6.97$ & $89.81 \pm 4.84$ \\
Arg & $99.28 \pm 2.42$ & $97.86 \pm 2.75$ & $99.58 \pm 1.54$ & $92.73 \pm 7.29$ \\
Total & $95.08 \pm 2.81$ & $93.49 \pm 11.22$ & $95.73 \pm 8.51$ & $88.17 \pm 2.41$ \\
\hline
\end{tabular}

Data represent the mean \pm SEM of 10 birds.

Table 12. Comparison of the true digestibility of amino acids at the distal end of the rectum. between groups $(\%)$

\begin{tabular}{ccccc}
\hline \hline \multirow{2}{*}{ Amino acid } & \multicolumn{4}{c}{ Dietary fat level $(\%)$} \\
\cline { 2 - 5 } & 3 & 5 & 8 & 10 \\
\hline Asp & $96.61 \pm 2.74$ & $96.69 \pm 6.55$ & $97.73 \pm 2.91$ & $95.79 \pm 6.14$ \\
Thr & $96.78 \pm 6.42$ & $97.23 \pm 9.77$ & $97.42 \pm 2.05$ & $90.87 \pm 6.29$ \\
Ser & $88.24 \pm 5.76$ & $88.79 \pm 8.09$ & $94.09 \pm 3.33$ & $94.09 \pm 3.33$ \\
Glu & $95.08 \pm 4.46$ & $94.85 \pm 9.32$ & $96.27 \pm 3.36$ & $96.27 \pm 3.36$ \\
Pro & $98.04 \pm 6.98$ & $97.84 \pm 5.51$ & $99.00 \pm 1.39$ & $99.00 \pm 1.39$ \\
Gly & $95.56 \pm 9.26$ & $93.84 \pm 5.51$ & $98.03 \pm 2.70$ & $98.03 \pm 2.70$ \\
Ala & $94.76 \pm 6.81$ & $95.39 \pm 7.46$ & $97.08 \pm 2.40$ & $97.08 \pm 2.40$ \\
Val & $96.08 \pm 7.70$ & $97.68 \pm 4.12$ & $98.24 \pm 1.18$ & $98.24 \pm 1.18$ \\
Met & $97.86 \pm 3.34$ & $97.23 \pm 9.77$ & $96.96 \pm 4.83$ & $96.96 \pm 4.83$ \\
Ile & $93.10 \pm 3.81$ & $94.66 \pm 6.32$ & $94.15 \pm 4.84$ & $94.15 \pm 4.84$ \\
Leu & $99.19 \pm 5.97$ & $99.01 \pm 2.92$ & $99.32 \pm 3.00$ & $99.32 \pm 3.00$ \\
Tyr & $98.44 \pm 5.47$ & $98.86 \pm 7.76$ & $98.94 \pm 3.80$ & $98.94 \pm 3.80$ \\
Phe & $99.40 \pm 8.48$ & $99.35 \pm 6.02$ & $99.66 \pm 0.92$ & $99.66 \pm 0.92$ \\
Lys & $98.30 \pm 6.12$ & $97.85 \pm 3.48$ & $98.57 \pm 1.95$ & $98.57 \pm 1.95$ \\
His & $98.48 \pm 6.54$ & $98.90 \pm 5.26$ & $98.97 \pm 2.10$ & $98.97 \pm 2.10$ \\
Arg & $99.29 \pm 2.44$ & $99.78 \pm 3.29$ & $99.66 \pm 2.23$ & $99.66 \pm 2.23$ \\
Total & $96.57 \pm 4.72$ & $96.75 \pm 11.69$ & $97.76 \pm 2.46$ & $97.32 \pm 2.11$ \\
\hline
\end{tabular}

Data represent the mean \pm SEM of 10 birds.

reported in the present study was similar to that in the previous study. In the previous study, corn oil was used as the sole source of dietary fat. On the other hand, tallow was used as the sole source of dietary fat in the present study. The underlying mechanisms still require clarification. However, there is evidence that dietary fat source influences the protein digestibility in growing broiler chickens (Crespo and Esteve-Garcia, 2002). Thus, it is possible that the difference of dietary fat source affects amino acid digestibility at the MJ in chickens.

In summary, we investigated the effects of dietary fat levels on the digestibilities of amino acids using fistulized chickens. Our results showed that digestibilities of most amino acids were decreased at the MJ in chickens fed the $10 \%$ fat diet. These results suggest that dietary fat levels influence the digestion of amino acids at the proximal part of the jejunum in chickens. 


\section{Acknowledgments}

This work was supported by a Grant-in-Aid for Scientific Research from the Ministry of Education, Culture, Sports, Science, and Technology of Japan.

\section{References}

Adedokun SA, Adeola O, Parsons CM, Lilburn MS and Applegate TJ. Standardized ileal amino acid digestibility of plant feedstuffs in broiler chickens and turkey poults using a nitrogen-free or casein diet. Poultry Science, 87: 2535-2548. 2008.

Adedokun SA, Parsons CM, Lilburn MS, Adeola $\mathrm{O}$ and Applegate TJ. Standardized ileal amino acid digestibility of meat and bone meal from different sources in broiler chicks and turkey poults with a nitrogen-free or casein diet. Poultry Science, 86: 2598-2607. 2007.

Association of Official Analytical Chemists. Official Methods of Analysis, 16th ed. (Cunnif $\mathrm{P}$ eds.). AOAC International, Virginia. 1995.

Bolin DW, King RP and Klosterman EW. A simplified method for the determination of chromic oxide $\left(\mathrm{Cr}_{2} \mathrm{O}_{3}\right)$ when used as an index substance. Science, 116: 634-635. 1952.

Cheeke PR. Applied Animal Nutrition, Feeds and Feeding. 2nd ed. Prentice Hall Inc.. New Jersey. 1999.

Crespo $\mathrm{N}$ and Esteve-Garcia E. Nutrient and fatty acid deposition in broilers fed different dietary fatty acid profiles. Poultry Science, 81: 1533-1542. 2002.

Duke GE and Evanson OA. Inhibition of gastric motility by duodenal contents in turkeys. Poultry Science, 51: 16251636. 1972.

Green S, Bertrand SL, Duron MJ and Maillard R. Digestibilities of amino acids in maize, wheat and barley meals, determined with intact and caecectomised cockerels. British Poultry Science, 28: 631-641. 1987a.

Green S, Bertrand SL, Duron MJ and Maillard R. Digestibilities of amino acids in soyabean, sunflower and groundnut meals, determined with intact and caecectomised cockerels. British Poultry Science, 28: 643-652. 1987b.

Honda K, Kamisoyama H, Isshiki Y and Hasegawa S. Effects of dietary fat levels on nutrient digestibility at different sites of chicken intestines. Journal of Poultry Science, 46: 291-295. 2009.

Hulan HW and Bird FH. Effect of fat level in isonitrogenous diets on the composition of avian pancreatic juice. Journal of Nutrition, 102: 459-468. 1972.

Huang KH, Li X, Ravindran V and Bryden WL. Comparison of apparent ileal amino acid digestibility of feed ingredients measured with broilers, layers, and roosters. Poultry Science, 85: 625-634. 2006.

Isshiki Y, Nakahiro Y, Yamauchi K and Zhou ZX. Fistulation technique for the middle and caudal parts of the jejunum and the middle part of the ileum in chickens. Japanese Poultry Science, 26: 314-321. 1989.

Johns DC, Low CK, Sedcole JR and James KA. Determination of amino acid digestibility using caecectomised and intact adult cockerels. British Poultry Science, 27: 451-461. 1986.

Kadim IT and Moughan PJ. Development of an ileal amino acid digestibility assay for the growing chicken - effects of time after feeding and site of sampling. British Poultry Science, 38: 89-95. 1997.

Kadim IT, Moughan PJ and Ravindran V. Ileal amino acid digestibility assay for the growing meat chicken - comparison of ileal and excreta amino acid digestibility in the chicken. British Poultry Science, 43: 588-597. 2002.

Kamisoyama H, Honda K, Isshiki Y and Hasegawa S. Effects of dietary protein levels on the nutrient digestibility at different sites of chicken intestines. Journal of Poultry Science, 46: 193-197. 2009.

Kamisoyama H, Honda K, Kubo S and Hasegawa S. Effects of dietary protein levels on amino acid digestibility at different sites of male adult chicken intestines. Journal of Poultry Science, 47: 220-226. 2010.

Kluth H, Mehlhorn K and Rodehutscord M. Studies on the intestine section to be sampled in broiler studies on precaecal amino acid digestibility. Archives of Animal Nutrition, 59: 271-279. 2005.

Larsen FM, Moughan PJ and Wilson MN. Dietary fiber viscosity and endogenous protein excretion at the terminal ileum of growing rats. Journal of Nutrition, 123: 1898-1904. 1993.

Longstaff M, McBain B and McNab JM. The antinutritive effect of proanthocyanidin-rich and proanthocyanidin-free hulls from field beans on digestion of nutrients and metabolisable energy in intact and caecectomised cockerels. Animal Feed Science and Technology, 34: 147-161. 1991.

Mateos GG and Sell JL. Influence of graded levels of fat on utilization of pure carbohydrate by the laying hen. Journal of Nutrition, 110: 1894-1903. 1980.

Ravindran V, He LI, Ravindran G and Bryden WL. A comparison of ileal digesta and excreta analysis for the determination of amino acid digestibility in food ingredients for poultry. British Poultry Science, 40: 266-274. 1999.

Rérat A. Digestion and absorption of carbohydrates and nitrogenous matters in the hindgut of the omnivorous nonruminant animal. Journal of Animal Science, 46: 1808-1837. 1978.

Rezvani M, Kluth H, Elwert C and Rodehutscord M. Effect of ileum segment and protein sources on net disappearance of crude protein and amino acids in laying hens. British Poultry Science, 49: 28-36. 2008a.

Rezvani M, Kluth $\mathrm{H}$ and Rodehutscord M. Comparison of amino acid digestibility determined prececally or based on total excretion of cecectomized laying hens. Poultry Science, 87: 2311-2319. 2008b.

Sakata T. Stimulatory effect of short-chain fatty acids on epithelial cell proliferation in the rat intestine: a possible explanation for trophic effects of fermentable fibre, gut microbes and luminal trophic factors. British Journal of Nutrition, 58: 95-103. 1987.

Ten Doeschate RAHM, Scheele CW, Schreurs VVAM and van der Klis JD. Digestibility studies in broiler chickens: influence of genotype, age, sex and method of determination. British Poultry Science, 34: 131-146. 1993.

Yokota $\mathrm{H}$ and Tasaki I. Site and rate of intestinal absorption of various amino acids in the chicken in situ. Japanese Journal of Zootechnical Science, 41: 209-215. 1970.

Whittow GC. Gastrointestinal anatomy and physiology. In: Sturkie's Avian Physiology fifth edition (Whittow GC eds.). pp. 299-325. Academic Press. London. 2000. 